\title{
Advancement, Characterization and Analogy of Jute Fabric and E-Glass Fibre Reinforced with Isophthalic Resin Based Composite
}

\author{
A.K. Arun Raja, D. Santhosh, K. Arun Vasantha Geethan, M. Suidarshanan, M. Suriya \\ Subramanian
}

\begin{abstract}
In recent years, there has been a growing need for natural fibre reinforced composite materials especially materials with good mechanical properties in order to substitute glass fibre based composite products to showcase a better engineering class for structural applications. Here the properties of jute fabric reinforced composite has been compared and analysed with e-glass fibre matte reinforced composite. The mercerized jute and e- glass fibre mats are treated with isophthalic resin. Charcoal powder has been used as a filler material constituting two percentage of the whole weight of entire composite. Isophthalic polyester resins offer substantially higher strength, better flexibility and chemical resistance. The properties of the jute composite and e-glass composite are determined by a series of tests such as Tensile, Flexural, Impact, Scanning Electron Microscopy (SEM) and Rate of Burning tests. The newly obtained composites provide a better usage for applications that require a much better physical strength and mechanical properties.
\end{abstract}

Keywords: Jute, E-glass, Isophthalic, Reinforcement, composite, Mercerization.

\section{INTRODUCTION}

In current scenario the concept of sustainability draws several experts and scientists towards the use of natural fibres as reinforcement in composites. The concern in this field is swiftly increasing both in research wise and in industrial operations . This is due to their high strength, corrosion resistance, less weight, renewability and stiffness to weight ratio. Several studies and researches has proved that the use of natural fibres has met the needs of sustainability, customer demands and all the environmental rules in the past few decades [1].Synthetic fibres may have high mechanical

Revised Manuscript Received on September 25, 2020.

* Correspondence Author

Mr. A. K. Arun Raja*, Assistant Professor in Mechanical Engineering Department St. Joseph's Institute of Technology, OMR, Chennai, Tamil Nadu, India.

Mr. D. Santhosh, Assistant Professor St. Joseph's Institute of Technology, OMR, Chennai, Tamil Nadu, India.

Dr. K. Arun Vasantha Geethan, Professor and the Head Of the Department of Mechanical Engineering St. Joseph's Institute of Technology, OMR, Chennai, Chennai, Tamil Nadu, India.

Mr. M. Suidarshanan, B. E. degree in Mechanical Engineering St. Joseph's Institute of Technology, OMR, Chennai, Tamil Nadu, India..

Mr. M. Suriya Subramanian, B. E. degree in mechanical engineering in St. Joseph's Institute of Technology, OMR, Chennai, Tamil Nadu, India.

(c) The Authors. Published by Blue Eyes Intelligence Engineering and Sciences Publication (BEIESP). This is an open access article under the CC BY-NC-ND license (http://creativecommons.org/licenses/by-nc-nd/4.0/) properties when compared to natural fibres but they are very costly and they can be mainly be concentrated only on aircraft and military applications. Recent studies have shown that the use of natural fibres can be increased by treating them properly with other fibres to increase the mechanical properties [2]. Natural fibres are now widely being used to restore synthetic components and its related products for energy management operations and low weight applications. Now a days the replacement of existing synthetic polymer reinforced materials with natural fibre reinforced polymer is huge. They are being actively used in automotive and aircraft industries for their internal components. A great deal of frequent research and studies often prove that the natural fibre reinforced green composites purifies the mechanical properties and prove to be ideal for many engineering applications [3]. Natural fibre composites can be very profitable in construction sectors, furnishings, electronics, cosmetics, medicines, fine chemicals and in various diverse applications. Main sources of natural fibres are plants. Jute appears to be the most favourable of all the natural fibres since it is economically available in appropriate form [4]. It is one of the most fast growing plants in India. Jute fibers can be obtained from both the inner stem and the outer skin of the jute stalk which are harvested by hand. It is a fairly rough fibre, which means that it is not typical for apparel operations .Instead its roughness and permanence makes it suitable for industrial operations. This fibre is favourable due to its contents of cellulose, hemicellulose, lignin and pentin. It absorbs water instantly but dries quickly. It is highly resistant to abrasion as well as stains and biodegrades quickly. Most types of jute fibres are light brown, but some off-white varieties are also obtained. Since it is sturdy and flexible, the fiber is generally easy to work with and is long and gleaming in its raw state. The study by Satyendra Pratap Singh Yadav shows that mechanical characteristics such as tensile and impact strength of jute fibre has enhanced with the use of epoxy resin [5]. This study looks whether there is improvement in the properties of fibre with the use of isophthalic resin. E-glass fibre is used in textile industry and for composites, its share reaching $90 \%$ of reinforcements. It is distinguished by its resistance to continuous high temperatures and its excellent electrical insulation properties. E glass fibre is rot resistant and can withstand the main chemical agents,

\section{Published By:}

Blue Eyes Intelligence Engineering and Sciences Publication

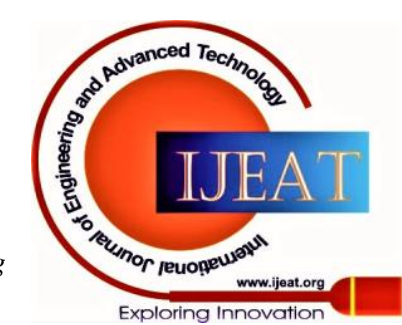




\section{Advancement, Characterization and Analogy of Jute Fabric and E-Glass Fibre Reinforced with Isophthalic Resin Based Composite}

remains stable even under intense variations of humidity and temperature. The tensile strength of e-glass fibre would be superior to that of the jute fibre, but the jute fibre is far more better than that of the glass in terms of specific modulus. The effects of jute fibre reinforcement and e-glass fibre reinforcement are studied and analysed in this work.

\section{EXPERIMENTAL PROCEDURE}

\section{A. Materials Used}

Jute and e-glass fibre are taken in mat form. For the fabrication process isophthalic polyester resin along with its corresponding hardener and accelerator are used. Jute fibre mat is purchased from the Association of Anakaputhur Jute Weavers- Pammal, Chennai. The E-glass fibre mat and the necessary isopththalic resin, hardener and accelerator are purchased from Shakthi Fibre Glass-Saidapet, Chennai.

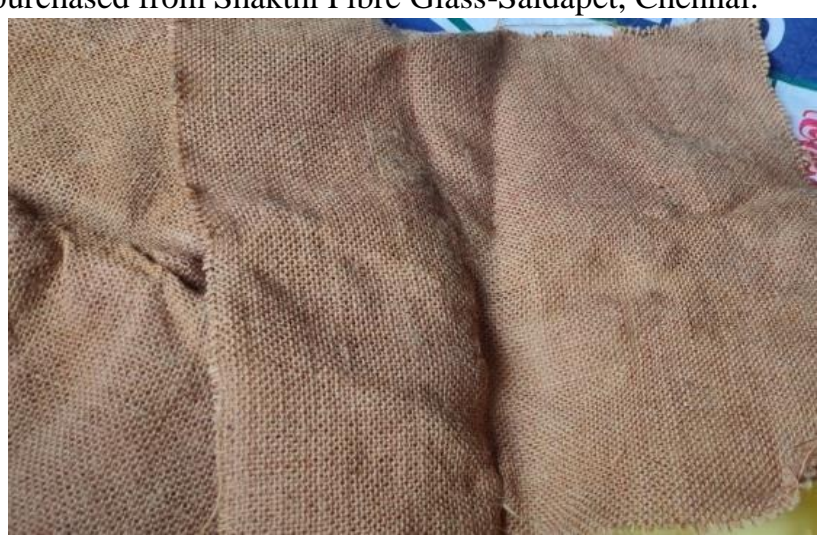

Fig 1: Jute Fibre Mat

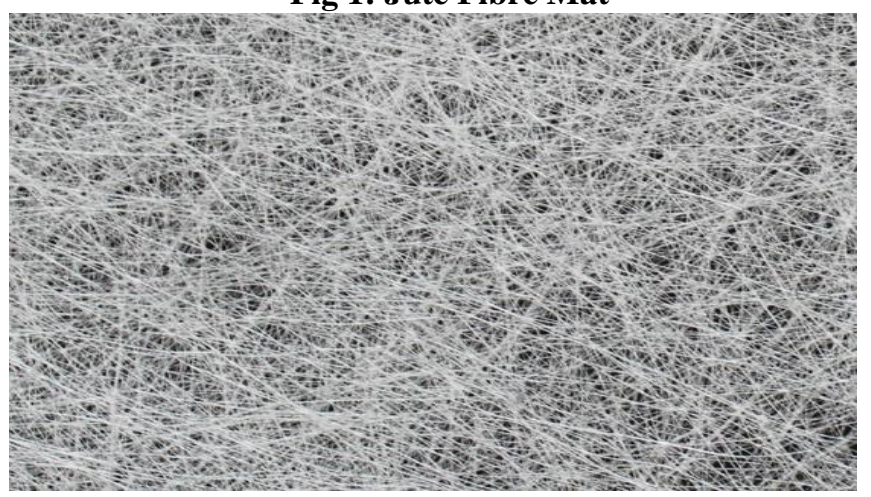

Fig 2: E-glass Fibre Mat

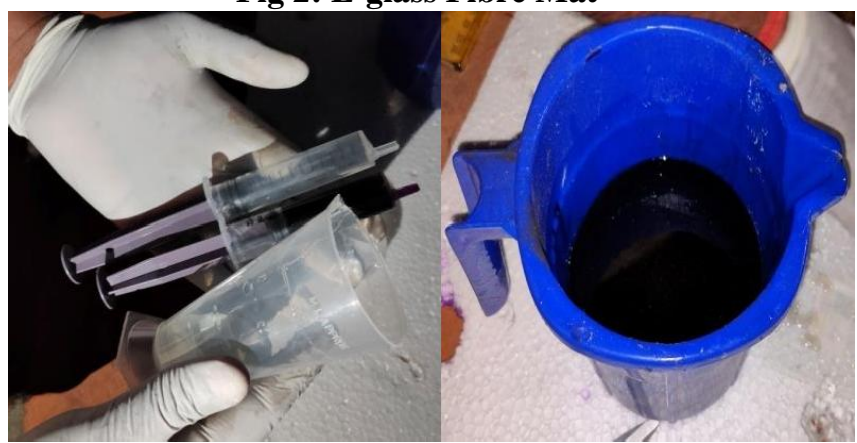

Fig 3: Beaker, syringe and isophthalic resin mixed with hardener and accelerator

\section{B. Mercerization}

The process of mercerization is usually done to increase the strength and prevent shrinkage. In this process the fibre is chemically treated with water containing 8 percent of sodium salts dissolved in it. The caustic rearranges the cellulose molecules in the fibre. Water containing 8 percent of $\mathrm{NAOH}$ solution is taken in a separate vessel. The jute fibre mat is immersed in the solution for 7-10 hours and then dried in room temperature for almost 2 days. This process makes it gentle and improves its strength. The corners of the fibre mat are then cut to obtain a perfect shape.

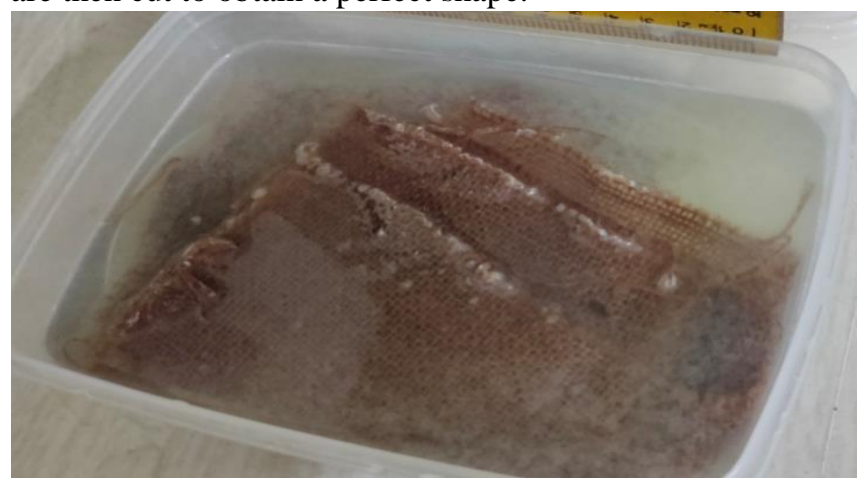

Fig 4: Mercerization

\section{Fabrication of Composite}

$800 \mathrm{ml}$ of isophthalic resin is filled in an empty container. Then the corresponding hardener and accelerator are mixed with the isophthalic resin in the ratio of 1:0.02 respectively. A filler material is must to improve the crosslink density and the internal bonding. The filler material used here is charcoal powder constituting 2 percentage of whole weight of the entire composite. A jute fabric and an e-glass fabric reinforced composite of same thickness is made. To make a composite two to three mats of fibre are joined with mixture of isophthalic resin and filler material in between them. The making is entirely done by hand moulding. The jute fibre reinforced composite and the e-glass fibre reinforced composite is made to dry completely. Then they are ready to be given for testing.

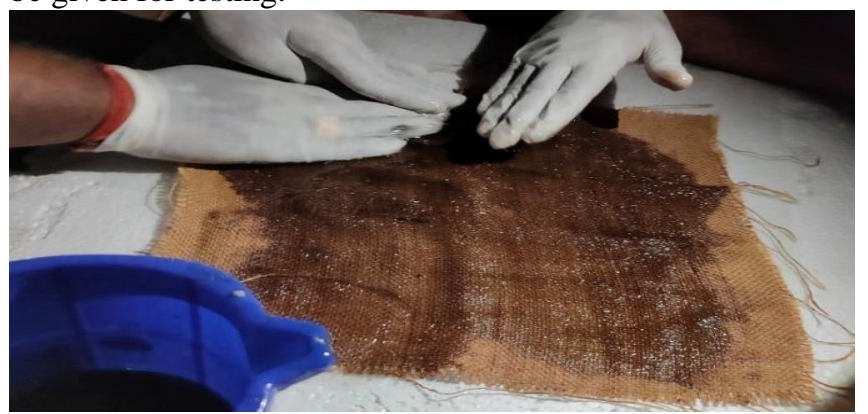

Fig 5: Making of Jute fibre reinforced composite

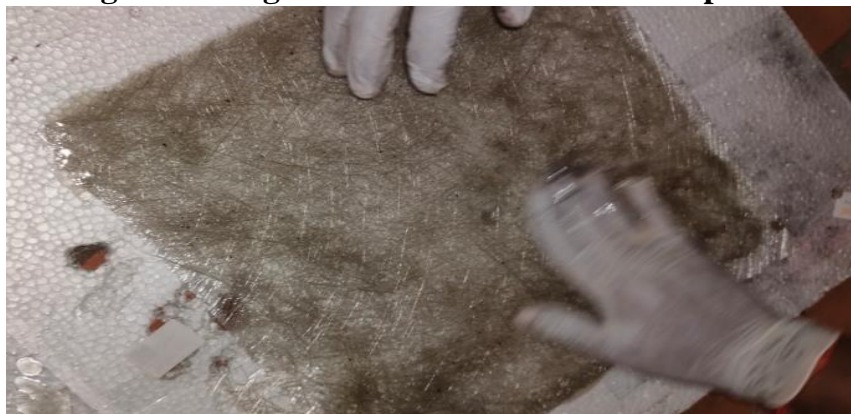

Fig 6: Making of E-Glass fibre reinforced composit

Published By:

Blue Eyes Intelligence Engineering and Sciences Publication

(C) Copyriaht: All riqhts reserved.

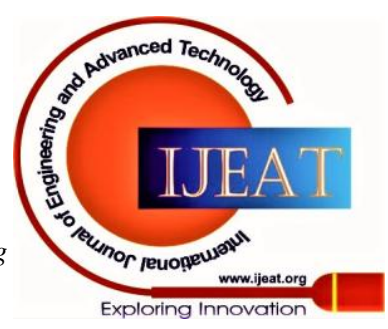




\section{TEST}

A number of mechanical tests are carried out in order for us to understand and examine the comparison between Isophthalic based Jute fibre and E-Glass fabric. These mechanical tests are carried out under the ASTM D standards. They are as follows:

\section{A. Tensile Test}

Tensile testing, also known as Tension testing is a destructive test process that provides information about the tensile strength, yield strength, and ductility of the metallic material. It measures the force required to break a composite or plastic specimen and the extent to which the specimen stretches or elongates to that breaking point. From this test, the strength of the material and the breaking point of the material to be tested can be determined. The tension strength and modulus strength are determined from the stress-strain curves. Jute fibres are able to withstand a higher load while redistributing a lesser load to the EFB fibres resulting in better tensile strength and modulus of the hybrid composites with the addition of jute fibres. Five samples were tested in each set and average is tabulated for each specimen. The machine used for tensile test is called Universal Testing Machine (UTM) shown in fig. This type of machine has two crossheads; one is adjusted for the length of the specimen and the other is driven to apply tension to the test specimen. There are two types: hydraulic powered and electromagnetically powered machines. The test specimens used were of size 120 $\mathrm{mm} \times 12.5 \mathrm{~mm}$ x $3 \mathrm{~mm}$. The picture below shows the machine used to perform the above test.

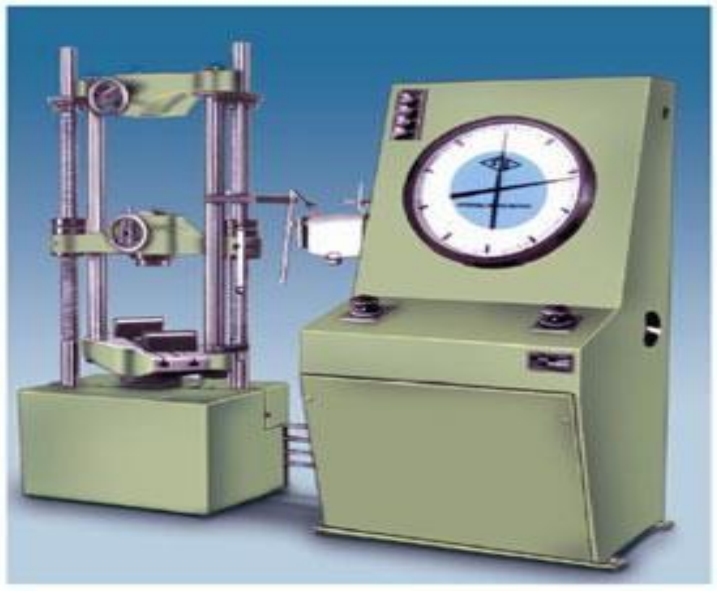

Fig 7: Universal Testing Machine (UTM)

\section{B. Flexural Test}

The most common purpose of a flexure test is to measure flexural strength and flexural modulus. Flexural strength is defined as the maximum stress at the outermost fibre on either the compression or tension side of the specimen. Flexural modulus is calculated from the slope of the stress vs. strain deflection curve. In simple words, Flexural strength is defined as the materials ability to resist deformation under load. The sample material is placed horizontally over two points of contact ( lower support span) and then a force is applied to the top of the material through either one or two points of contact ( upper loading span) until the sample fails. The maximum recorded force is the flexural strength of that sample. The flexural modulus of the material is directly proportional to fibre loading.

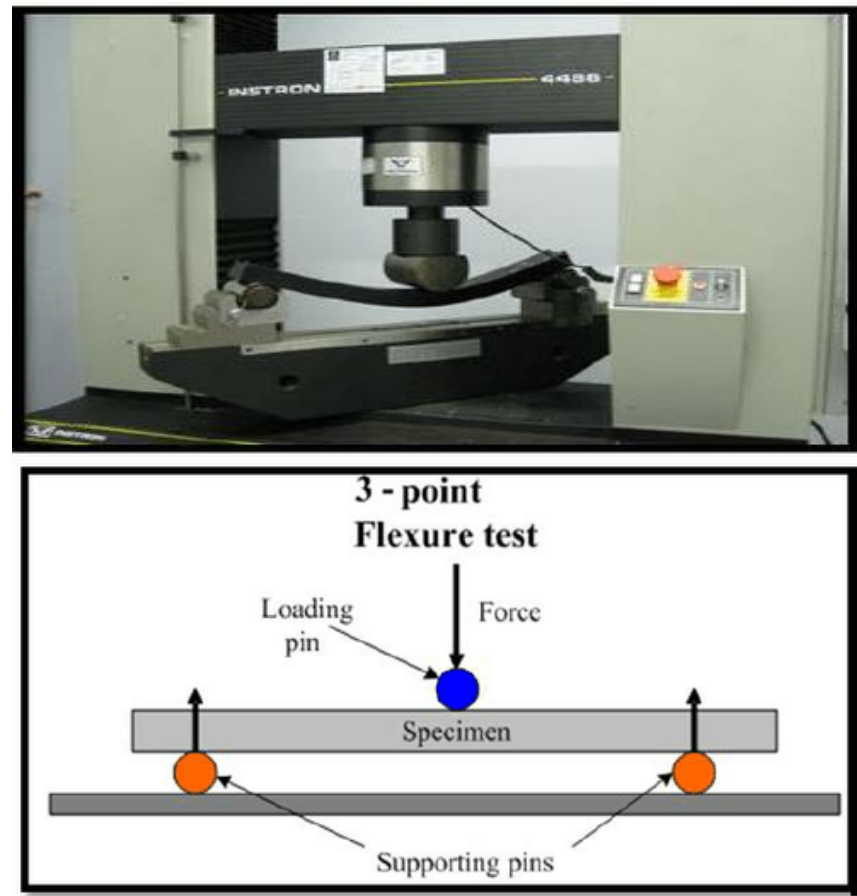

Fig 8: Representation of 3-point Flexural Testing

\section{Compression Test}

Compression testing is used to determine how a product or material reacts when it is compressed, squashed, crushed or flattened by measuring fundamental parameters that determine the specimen behavior under a compressive load. Compression tests are conducted by loading the test specimen between two plates, and then applying a force to the specimen by moving the crossheads together. During the test, the specimen is compressed, and deformation versus the applied load is recorded. The compression test is used to determine elastic limit, proportional limit, yield point, yield strength, and (for some materials) compressive strength. The samples are taken at the dimensions of $120 \mathrm{~mm} \times 12.5 \mathrm{~mm} \times 3 \mathrm{~mm}$. The compression test is carried out in the universal testing machine. The samples are loaded in the machine and results are tabulated.

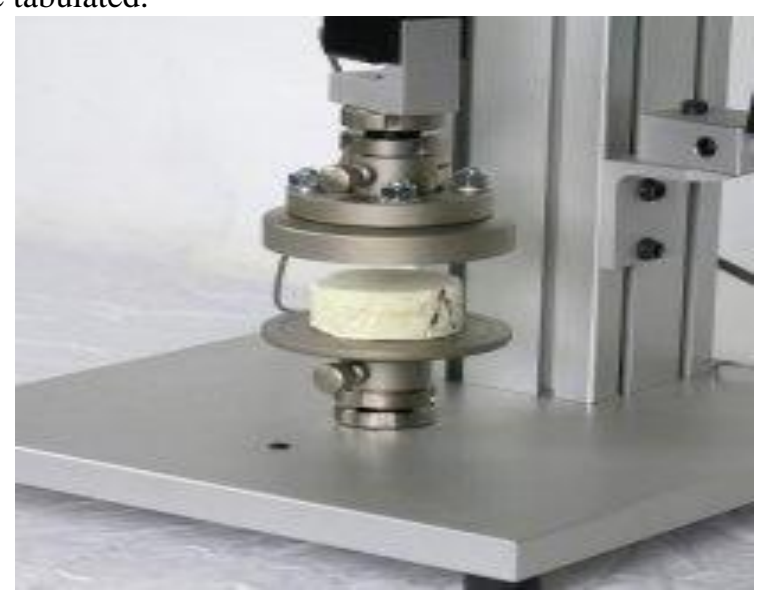

Fig 9: A pictorial example of compression

Published By:

Blue Eyes Intelligence Engineering and Sciences Publication

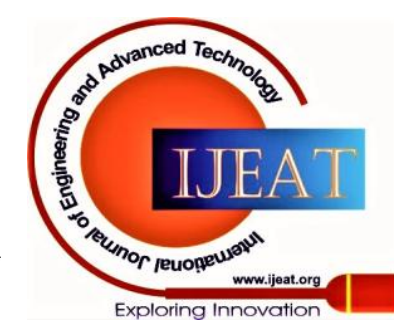


Advancement, Characterization and Analogy of Jute Fabric and E-Glass Fibre Reinforced with Isophthalic Resin Based Composite

\section{Impact Test}

An impact test is used to observe the mechanics that a material will exhibit when it experiences a shock loading that causes the specimen to immediately deform, fracture or rupture completely. The purpose of an impact test is to determine the ability of the material to absorb energy during a collision. This energy may be used to determine the toughness, impact strength, fracture resistance, impact resistance or fracture resistance of the material depending on the test that was performed and the characteristic that is to be determined. To perform this test the sample is placed into a holding fixture with the geometry and orientation determined by the type of test that is used and then a known weight generally but not always in the shape of a pendulum is released from a known height so that it collides with the specimen with a sudden force. This collision between the weight and specimen generally results in the destruction of the specimen but the transfer of energy between the two is used to determine the fracture mechanics of the material. Generally, at lower temperatures, the impact energy of a material is decreased. For each set, a sample of 5 is taken and the average is determined.

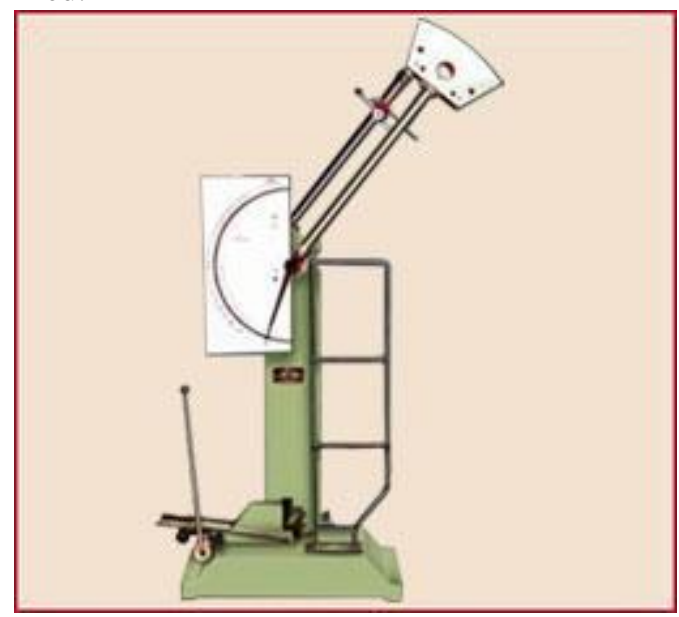

Fig 10: Impact Testing Machine

\section{E. Rate of Burning Test}

In this test, the measurement of a material's flammability and rate of combustibility of that material is used to determine the rate of burning of the specimen. Initially the test specimen is horizontally supported on one end, and the free end is exposed to a flame of gas for 30 seconds. After removal of the flame, the test specimen is observed for time and extent of burning. An average burning rate is reported for the composite up to the burnt mark from the ignited end.

\section{RESULT AND DISCUSSION}

The results are acquired from the average value obtained from the following tests mentioned. A number of five samples are used for the testing. The average value is calculated and the results are tabulated and the graphical representation for the results are made. The samples are tagged as A \& B.

A - Jute fibre composite

B - E-Glass fabric composite

\section{A. Mechanical Properties}

Contemplating The Mechanical features which are tabulated below in Table 1 it could be deduced that E- Glass Fibre has relatively superior Mechanical properties than Jute fabric, but there is not much difference.

Table 1

\begin{tabular}{|l|c|c||c|}
\hline SPECIMEN & $\begin{array}{c}\text { TENSILE } \\
\text { STRENGTH }\end{array}$ & $\begin{array}{c}\text { FLEXURAL } \\
\text { LOAD }\end{array}$ & $\begin{array}{c}\text { IMPACT } \\
\text { VALUES }\end{array}$ \\
\hline UNITS & $(\mathrm{MPa})$ & $(\mathrm{KN})$ & JOULES \\
\hline $\mathrm{A}$ & 26.36 & 0.37 & 10 \\
\hline $\mathrm{B}$ & 46.92 & 0.32 & 12 \\
\hline
\end{tabular}

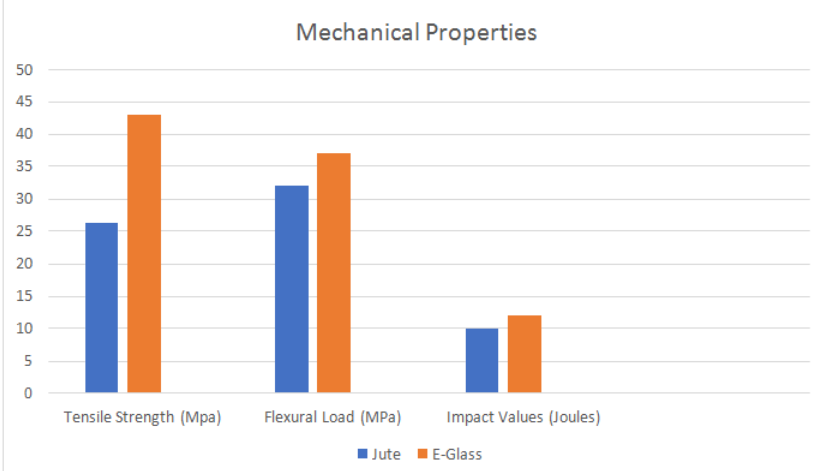

Fig 11: Comparison of mechanical properties between Jute and E-Glass fibre.

\section{B. Rate of Burning}

When it comes to Rate of burning, E-Glass composite has slightly higher value compared to the Jute fabric composite and the applications based on this property varies accordingly

Table 2

\begin{tabular}{|l|l|}
\hline SPECIMEN & RATE OF BURNING \\
\hline UNITS & $(\mathrm{mm} / \mathrm{min})$ \\
\hline A & 11.74 \\
\hline B & 16.34 \\
\hline
\end{tabular}

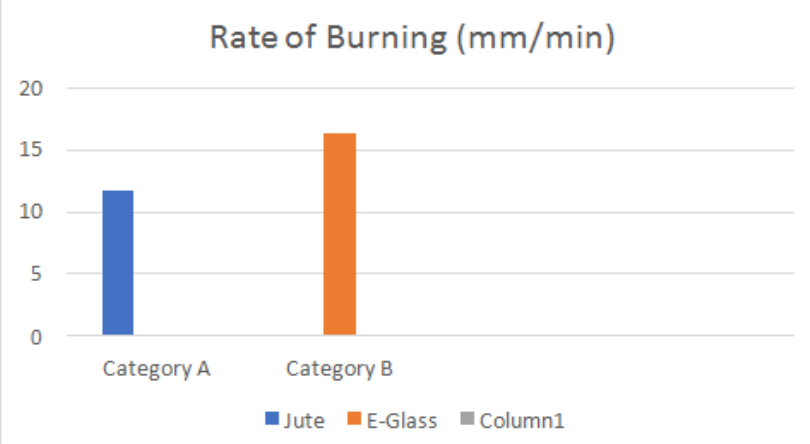

Fig 12: Comparing Jute and E-Glass fibre based On Rate of burning 


\section{SURFACE TOPOLOGY}

A scanning electron microscope (SEM) scans a focused electron beam over a surface to create an image. The electrons in the beam interact with the sample, producing various signals that can be used to obtain information about the surface topography and composition. The scanning electron microscope (SEM) uses a focused beam of high-energy electrons to generate a variety of signals at the surface of solid specimens. The signals that derive from electron-sample interactions reveal information about the sample including external morphology (texture), chemical composition, and crystalline structure and orientation of materials making up the sample. The signals used by a scanning electron microscope to produce an image result from interactions of the electron beam with atoms at various depths within the sample. Various types of signals are produced including secondary electrons (SE), reflected or back-scattered electrons (BSE), characteristic X-rays and light (cathodoluminescence) (CL), absorbed current (specimen current) and transmitted electrons. Secondary electron detectors are standard equipment in all SEMs, but it is rare for a single machine to have detectors for all other possible signals.

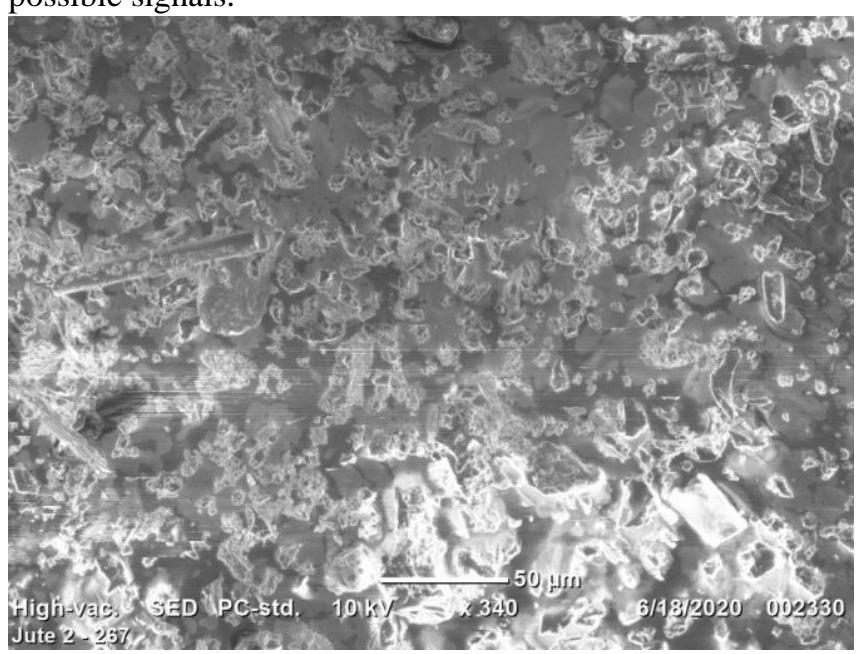

Fig 13: SEM image of jute composite before impact

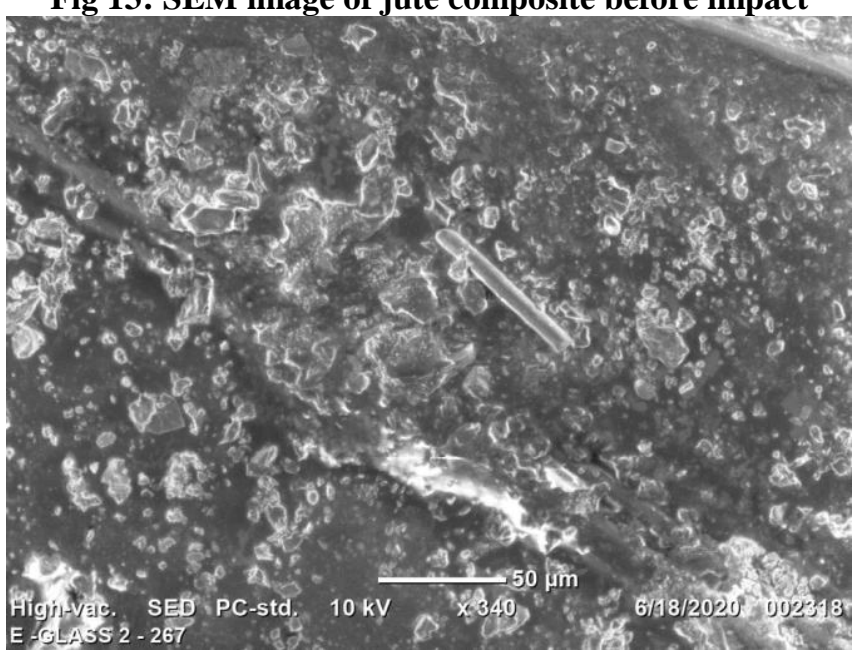

Fig 14: SEM image of E-Glass composite before impact

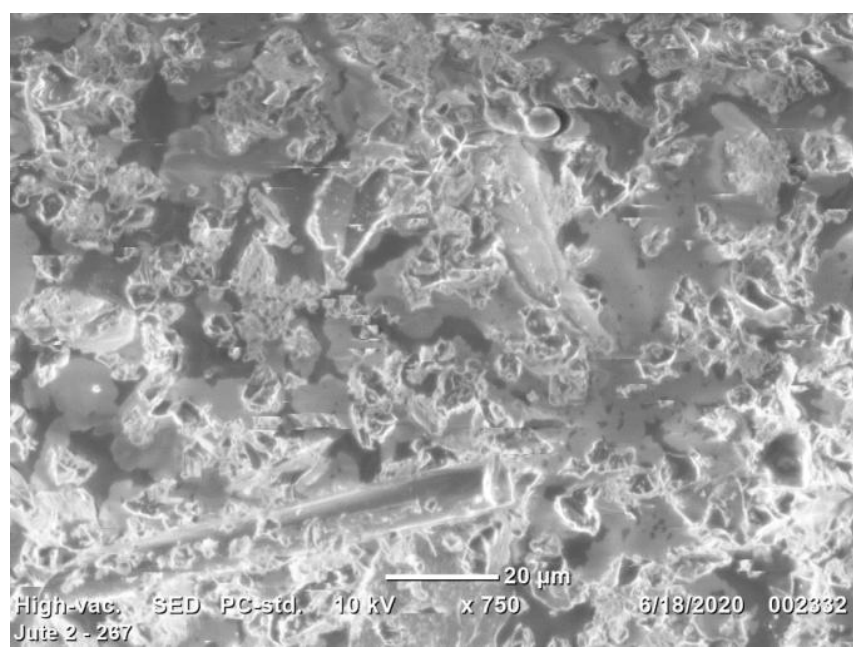

Fig 15: SEM image of Jute composite after impact

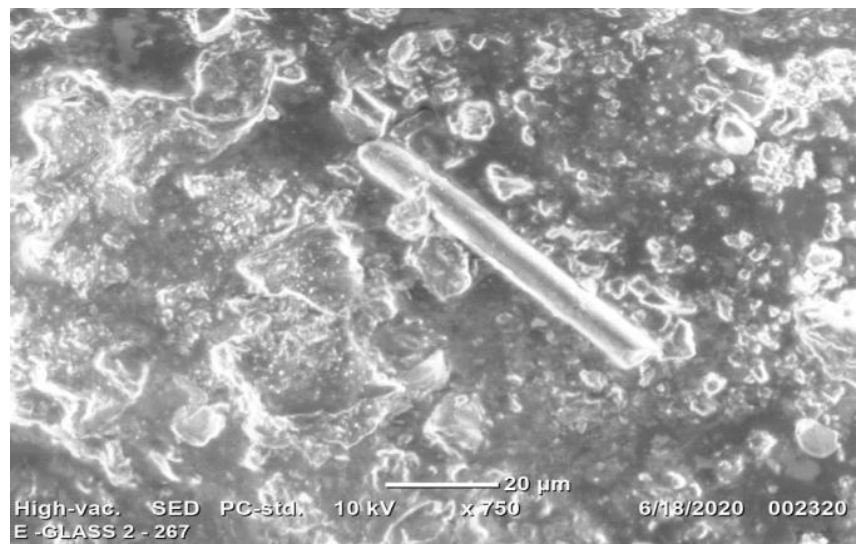

Fig 16: SEM image of E-Glass composite after impact

\section{CONCLUSION}

In today's growing world of extensive usage of natural fibre as reinforcement has been proven as eco-friendly alternative to traditional synthetic fibres. Also studies has been made to compare the mechanical strength of Jute Fibre and E-glass fibre reinforced composite, with an outcome proving the following conclusions.

- Mechanical properties of Jute Fabric composite are almost similar to the E-glass fabric in all aspects, but considering the environmental welfare it is wise to use natural based natural Jute fabric composite over E-glass composites.

- Since both Jute fibre and E-glass fibre has almost the same hardness level it can replace the E-glass Fibre in Hardness oriented applications.

- Both the Jute Fibre and E-glass composite shows almost the same rate of burning it could also very well be used in the field of Thermal applications.

- SEM image shows that Jute fabric composite has better structural integrity compared to E- Glass fabric composite even following impact.

- At the top of this research, it is also found that addition of filler materials and resins on Jute fabric mat is recommended, in order to improve the mechanical property and structural integrity of Jute fibres to show better results.

DOI:10.35940/ijeat.A1753.1010120

\section{Published By:}

Blue Eyes Intelligence Engineering

and Sciences Publication
(c) Copyright: All rights reserved.

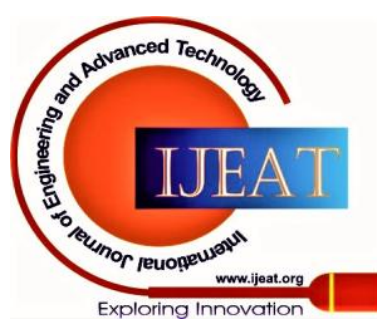




\section{Advancement, Characterization and Analogy of Jute Fabric and E-Glass Fibre Reinforced with Isophthalic}

Resin Based Composite

\section{REFERENCES}

1. Soma Dalbehra, S.K. Acharya, "Study on mechanical properties of natural fiber reinforced woven jute-glass hybrid epoxy composites".

2. B. Vijayaramnath, S. Junaid Kokan, R. Niranjan Raja, R. Sathyanarayanan, C. Elanchezhian, A. Rajendra Prasad, V.M. Manickavasagam, "Evaluation of mechanical properties of abaca-jute-glass fibre reinforced epoxy composite".

3. Harpreet Singh, Jai Inder Preet Singh,Sehijpal Singh, Vikas Dhawan, Sunil Ku ar Tiwari, "A Brief Review of Jute Fibre and Its Composites".

4. M. R. Sanjay, B. Yogesha, "Studies on Mechanical Properties of Jute/E-Glass Fiber Reinforced Epoxy Hybrid Composites".

5. Satyendra Pratap Singh Yadav, Dr. A.S. Verma, "Fabrication of composite material using Jute fiber/Glass fiber".

6. Harpreet Singh, Jai Inder Preet Singh, Sehijpal Singh, Vikas Dhawan, Sunil Kumar Tiwari, "A Brief Review of Jute Fibre and Its Composites".

7. Sekhar Das, Amiya Kumar Singha, Atin Chaudhuri \& Prasanta Kumar Ganguly, "Lengthwise Jute Fibre Properties Variation And Its Effect On Jute-Polyester Composite".

8. Kanishka Jha, Bibhuti Bhusan Samantaray, Paresh Tamrakar, "A Study on Erosion and Mechanical Behavior of Jute/E-Glass Hybrid Composite".

9. Elsayed A. Elbadry, Mohamed S. Aly-Hassan, Hiroyuki Hamada, "Mechanical Properties of Natural Jute Fabric/Jute Mat Fiber Reinforced Polymer Matrix Hybrid Composites".

10. Gowda T.M, Naidu A.C.B. and Chhaya R, "Some Mechanical Properties of Untreated Jute Fabric Reinforced Polyester Composites".

11. Hong C.K, Hwang I, Kim N, Park D.H, Hwang B.S and Nah C, "Mechanical Properties of Silanized Jute-Polypropylene Composites".

12. Bledzki A.K and Gassan J, "Composites Reinforced With Cellulose Based Fibres".

\section{AUTHORS PROFILE}

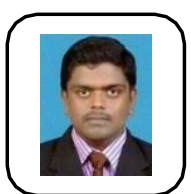

Mr. A. K. Arun Raja p is working as an Assistan Professor in Mechanical Engineering Department in St. Joseph's Institute of Technology, OMR, Chennai, Tamil Nadu, India. He has a work experience of 7 years as assistant professor. He is currently pursuing his $\mathrm{Ph} . \mathrm{D}$. from Sathyabama University, OMR, Chennai, Tamil Nadu, India, in the topic "Bio Composites". He has done a total of 8 publications including Scopus and sci indexed journals. He has guided number of college students in completing their project on natural reinforced composites.

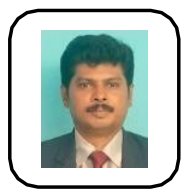

Mr. D. Santhosh is working as an Assistant Professor in St. Joseph's Institute of Technology, OMR, Chennai, Tamil Nadu, India. He is a topper and an Anna University medalist for M.E Manufacturing Engineering, with a total of 3 Scopus Indexed Publications. He is guiding college students for completing their projects.

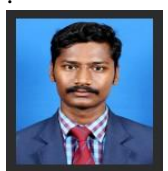

Dr. K. Arun Vasantha Geethan is working as a Professor and the Head Of the Department of Mechanical Engineering in St. Joseph's Institute of Technology, OMR, Chennai, Chennai, Tamil Nadu, India. He has a work experience of about 14 years in the field of teaching. He has done his Masters in Anna University, Chennai. He is also awarded with Doctor of Philosophy in "Reverse supply chain management" as area of research. He has a total of 26 publications including SCI and Scopus Indexed Journals.

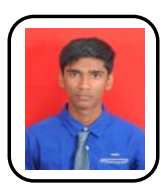

Mr. M. Suidarshanan is a Final year student pursuing his B E. degree in mechanical engineering in St. Joseph's Institute of Technology, OMR, Chennai, Tamil Nadu, India.. He has done an academic project in "Design and Fabrication". He has completed a project for TVS Motors under the guidance of MSME-CDCE Automation. He has also attended a lot of workshops and done In-plant trainings in notable companies. He has also visited several industries with the help of his college.

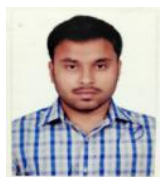

Mr. M. Suriya Subramanian is a Final year student pursuing his B. E. degree in mechanical engineering in St. Joseph's Institute of Technology, OMR, Chennai, Tamil Nadu, India.. He has done an academic project in "Design and Fabrication". He has completed a project for TVS Motors under the guidance of MSME-CDCE Automation.
He has also attended a lot of workshops and done In-plant trainings in notable companies. He has also visited several industries with the help of his college along with the previous author.

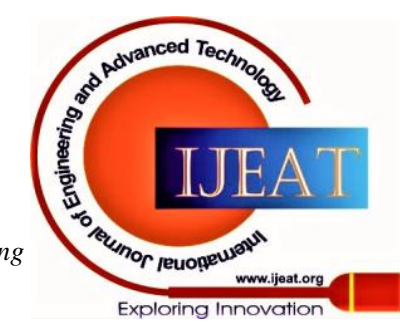

